Results: We enrolled 147 patients, out of them 66 patients were on monotherapy with Abatacept due to intolerance or controindications and 81 in therapy with Abatacept plus MTX. The two cohorts appeared homogeneous in age, gender, disease duration and baseline activity indexes, with the only difference being higher baseline Physician Global assessment (PhGA) values in monotherapy patients. During the follow-up (median duration $24 \pm 14$ months), the retention rate of Abatacept treatment was $71.2 \%$ in MTX patients (median duration 27-15.6 months) and $62.1 \%$ in monotherapy patients (median duration 25.2-17.5; $p=n s$ ). No differences between the two groups in terms of retention rate, low-disease activity and CDAI remission (log rank $p=n s$ ), Breslow $p=n s$ ) were detected.

Conclusion: In patients with RA with intolerance or contraindication to MTX use, Abatacept monotherapy could be an efficient and safe option even in the long term follow-up.

References: [1]Abatacept monotherapy compared with abatacept plus disease-modifying anti-rheumatic drugs in rheumatoid arthritis patients: data from the ORA registry. Truchetet ME et al. Arthritis Res Ther. 2016 Mar 30;18:72. Disclosure of Interests: DANIELA IACONO Speakers bureau: PFIZER, BRISTOL MAYERS SQUIBB, SANOFI, Ilenia Pantano: None declared, domenico birra: None declared, GIUSEPPE SCALISE: None declared, Melania Alessia Coscia: None declared, VALENTINA MESSINITI: None declared, Gabriella Loi: None declared, Anna Merchionda: None declared, Paolo Moscato: None declared, francesco ciccia Grant/research support from: pfizer, novartis, roche, Consultant of: pfizer, novartis, lilly, abbvie, Speakers bureau: pfizer, novartis, lilly, abbvie

DOI: 10.1136/annrheumdis-2020-eular.5780

\section{AB0316 $\quad$ MULTIPLE SWITCH BETWEEN BIOSIMILARS DMARDS (BSDMARDS) IN PATIENTS WITH INFLAMMATORY ARTHRITIDES: EXPERIENCE OF A SINGLE ITALIAN CENTRE}

M. Riva ${ }^{1}$, V. Varisco', L. Riva ${ }^{1}$, F. Rumi ${ }^{2}$, M. R. Pozzi ${ }^{1}{ }^{1} S S D$ Reumatologia ASST-Monza, Ospedale San Gerardo dei Tintori, Monza, Italy; ${ }^{2}$ Unità di Epidemiologia, Società Italiana di Reumatologia, Milano, Italy

Background: The availability of bsDMARDs since some years represents an opportunity to improve patient access to effective biologic therapy, to better accommodate restraints within healthcare budgets and to improve overall patient outcomes. Different policies are followed in different countries to implement the use of bsDMARDs. Although the latest position paper of AIFA (Agenzia Italiana del Farmaco) envisions the automatic sostitution between the originator and biosimilar, until now the prescriber decision and the patient consent are strongly advised. The question around biosimilar to biosimilar switching is overlooked. Nevertheless different rules are established at regional level and in our Hospital automatic switching between originator/biosimilar and biosimilar/biosimilar was applied.

Objectives: To analyze the efficacy and safety of switch from originator to biosimilar $(\mathrm{O} / \mathrm{B})$ and/or biosimilar to biosimilar $(\mathrm{B} / \mathrm{B})$ in patients with $\mathrm{RA}, \mathrm{Ps} A$ and SpA.

Methods: We retrospectively analyzed in 63 patients $(30 \mathrm{~F}$, mean age 58.3 yr, 21 RA, 26 PsA, $16 \mathrm{SpA}$ ), treated with Infliximab, Etanercept and Adalimumab, disease activity (DAS28 CRP for RA, Tender/Swollen joint count for PsA, BASDAI for SpA, CRP for all) and adverse events/infections (AE). The time points considered were $3^{\text {rd }}$ month before the switch and $3^{\text {rd }}$ and $6^{\text {th }}$ month after.

Results: 45 patients underwent sigle switch (35 O/B, 9 B/B) and 18 (28.5\%) double switch (O/B/B). 27 B/B switch were done. No differences in disease activity were observed before and after switch (8 RA patients: mDAS28 CRP 2.86>3.23, 11 PsA patients: $\mathrm{mTJ}$ count $2.5>3.43,8 \mathrm{SpA}$ patients: BASDAI 2.88 > 2.84). The mean number of swollen joints was very low in PsA group and we decided to exclude this variable. The CRP level was low and stable along all period examined in the three groups. No increase in steroid daily dose, nor in concomitant DMARDs therapy was reported. In the Etanercept $B / B$ switch (14 pts) the number of infections was the same before (3) and after (3). In Infliximab B/B switch (13 pts) 3 infections were reported only before the switch. The severity was mild/moderate with prevalence of respiratory infections $(57 \%)$. No remarkable variation of transaminases and blood counts were observed.

Conclusion: Althoug the population we examined was eterogeneous and quite small, we observed that the efficay and safety of Infliximab and Etanercept are maintained with biosimilar to biosimilar switch, also after double switch (originator>biosimilar>biosimilar). We also can confirm that the switch from originator to biosimilar Infliximab, Etanercept and Adalimumab is safe in our experience.

Disclosure of Interests: None declared

DOI: 10.1136/annrheumdis-2020-eular.6268

\section{$\mathrm{AB} 0317$ BIOLOGIC THERAPY OPTIMIZATION IN RHEUMATOID ARTHRITIS PATIENTS IN COLOMBIA}

W. G. Rojas Zuleta ${ }^{1}$, O. J. Felipe Díaz ${ }^{1}$, A. E. Pantoja Marquez ${ }^{1}$, R. Giraldo ${ }^{1}$, J. G. López Velandia ${ }^{1}$, E. P. Navarro Mendoza ${ }^{1}$, C. Orozco Gonzalez ${ }^{2}$, J. Barbosa Camacho ${ }^{2}$, N. Duque Zapata ${ }^{2}$, J. Donado Gómez ${ }^{2} .{ }^{1}$ Medicarte, Rheumatology, Medellin, Colombia; ${ }^{2}$ Medicarte, Epidemiologist, Medicarte Research Group (MRG), Medellín, Colombia

Background: The optimization of biological agents (bDMARD), is a strategy that has proven to be cost effective and its use can reduce the risk related to drug exposure (1-3). It is included in the EULAR management guidelines and in the consensus of the Colombian Rheumatology Association.

Objectives: To analyze optimization success of bDMARD therapies in patients with RA.

Methods: Cohort study of RA patients in a specialized multicenter institution in Colombia, followed from January 2015 to December 2019. Patients in remission or low activity for at least 6 months with bDMARD, and with at least two consecutive medical visits, were included. Optimization types were dose decrease, application interval increments, or both. Patients who had disease reactivation (DAS28- CPR >3.2) and returned to standard dose, were considered a failure. By Kaplan-Meier analysis, the optimization failure was estimated according to bDMARD type

Results: 92 patients were included, $78.26 \%$ were women, with a median age of 57 years (IQR 50-64), a disease evolution time of 15 years (IQR 10-21), a treatment of 5.6 years (IQR 2.7-8.0), and optimization of 7.75 months (IQR 3.2515.75). The most commonly used bDMARD therapies were etanercept $36.96 \%$, tocilizumab $30.43 \%$ and adalimumab $16.30 \%$. 69.39\% (34) were naive for biological treatment. The $53.26 \%$ (49) of patients had a follow-up time greater than 6 months.

95.92\% remained under optimization scheme without disease activity changes, and $4.08 \%$ of patients underwent definitive discontinuation of bDMARD, for sustained therapeutic objective. $8.16 \%$ (4) had relapses in the first 6 months after onset, of which 2 patients returned to standard doses. In survival analysis it was observed that patients who were optimized for antiTNF failed faster than the non-antiTNF, although this difference was not statistically significant (Log Rank test $0.003 p$ value $=0.959$ ). Of the total patients, 28 have been optimized for 12 months or more, of these, $96.43 \%$ (27) continue in sustained remission, and $55.56 \%$ (15) received combined therapy with s synthetic DMARD (sDMARD).

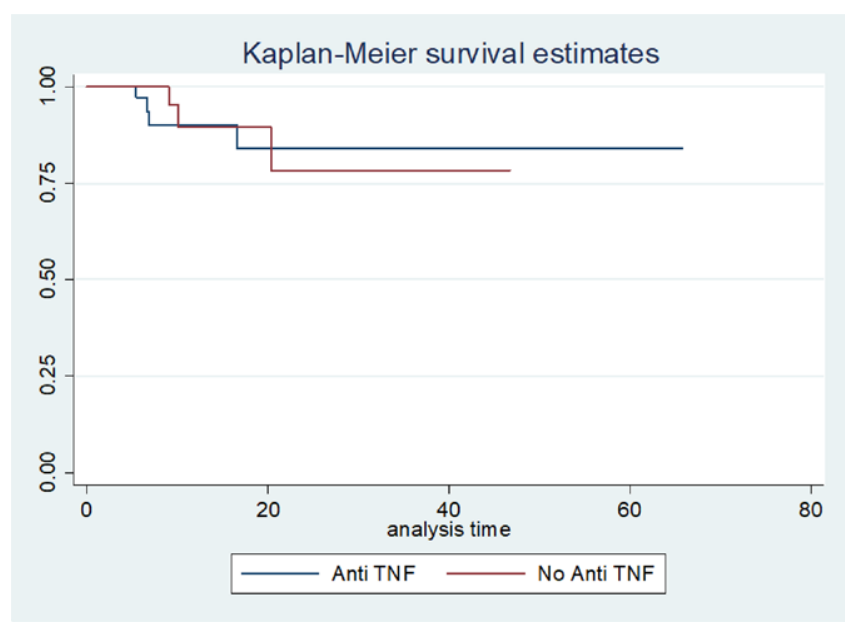

Figure 1. Kaplan Meier

Conclusion: During follow-up, most patients remain in optimization strategy. In those who continued in sustained remission, more than half received SDMARD, this suggests that their use may be a determining factor in preventing disease relapses. More studies are required to evaluate this hypothesis.

\section{References:}

[1] Niccoli L, Nannini C, Blandizzi C. Personalization of biologic therapy in patients with rheumatoid arthritis: Less frequently accounted choice-driving variables. Ther Clin Risk Manag. 2018;14:2097-111.

[2] ASOREUMA. Asociación Colombiana de Reumatología. Consenso sobre recomendaciones para disminución y descontinuación de la terapia biológica en pacientes con artritis reumatoide, espondilitis anquilosante y artritis psoriásica. Rev Colomb Reumatol. 2019 Jan;26(1):11-23. 